\title{
Jovens, juventude e políticas públicas: Produção acadêmica em periódicos científicos brasileiros (2002 a 2011).
}

\author{
Andréa Vieira Zanella \\ Apoliana Regina Groff \\ Universidade Federal de Santa Catarina \\ Dâmaris Oliveira Batista da Silva \\ Universidade do Sul de Santa Catarina \\ Laura Kemp de Mattos \\ Janaína Rocha Furtado \\ Universidade Federal de Santa Catarina \\ Neiva de Assis \\ Instituto Federal de Santa Catarina
}

\begin{abstract}
Resumo
Neste artigo discute-se a produção acadêmica entre 2002 e 2011 sobre jovem, juventude e políticas públicas, divulgada em periódicos científicos brasileiros que integram a base de dados SCIELO. Os artigos selecionados foram categorizados em relação à instituição de origem, titulação dos pesquisadores, área do conhecimento da publicação e dos pesquisadores, ano de publicação do artigo, tipo de pesquisa, objetivos, recursos metodológicos, concepção de jovem, juventude e políticas públicas. Constatamos uma concentração de estudos nas áreas de educação, saúde e assistência social. Quanto às concepções de jovem e juventude, predominou a concepção de sujeito com base em fases e estágios claramente marcados pela entrada e saída do trabalho, sendo evidente nesses estudos a lógica de que a tutela se faz necessária, seja da família, do Estado e de Instituições outras, inclusive a Acadêmica. Sob essa lógica se apresentam grande parte das justificativas para a reivindicação de políticas públicas para os jovens nos artigos analisados.
\end{abstract}

Palavras-chave: jovens; juventude; políticas públicas.

\begin{abstract}
Young, youth and public policies: Academic production in brazilian scientific journals (from 2002 to 2011). This article discusses the research conducted between 2002 and 2011 on young, youth and public policy, published in Brazilian scientific journals that comprise the database SCIELO. The selected articles were categorized in relation to the home institution, titrations researchers, knowledge area and the publication of research, publication year of the article, type of research, objectives, methodological resources, concept of young, youth and public policy. We found a concentration of studies in the areas of education, health and social care. About conceptions of youth and youth predominated the concept of subject based on phases and stages clearly marked by the entry and exit of the work, being evident in these studies the logic that the guardianship is necessary, by the family, the State and other institutions, including the Academic. Under this logic is present most of the justifications for the claim of public policies for the youth in the analyzed articles.
\end{abstract}

Keywords: young; youth; public policies.

\section{Resumen}

Juventud, los jóvenes y las politicas públicas: La producción académica en revistas científicas brasileñas (2002-2011). En este artículo se discute la investigación desarrollada entre 2002 y 2011 con los jóvenes, la juventud y las políticas públicas, publicada en revistas brasileñas que integran la base de datos SciELO. Artículos seleccionados se clasificaron en relación con la institución de origen, la titulación de los investigadores, área de conocimiento de la publicación de los investigadores, el año de publicación del artículo, el tipo de investigación, objetivos, recursos metodológicos, la definición de los jóvenes, la juventud y las políticas públicas. Hemos encontrado una concentración de estudios en las áreas de educación, salud y asistencia social. Así como los conceptos de juventud, la comprensión predominante de sujeto es basado en fases y etapas claramente marcadas por la entrada y salida del trabajo, siendo evidente en estos estudios la lógica de que la tutela es necesaria, sea por la familia, por el Estado y otras instituciones, incluido el académico. Subyacente a esta lógica está presente la mayor parte de la justificación de la demanda de políticas públicas para los jóvenes en los artículos analizados.

Palabras clave: joven; juventud; políticas públicas. 
$\mathrm{E}$ m clássico texto sobre juventude no Brasil Abramo (1997) salienta o aumento da atenção dirigida aos jovens no país, o que pode ser constatado por toda a década de 90 até recentemente. A importância dada aos jovens, tanto pela academia, pela mídia ou por atores e instituições políticas, governamentais e não governamentais, advém da mobilização em defesa dos direitos das crianças e dos adolescentes nas décadas de 70 e 80, o que resultou no Estatuto da Criança e do Adolescente (ECA).

$\mathrm{Na}$ década de 90 eclode, contudo, um novo interesse sobre o tema provocado pelos recidivos processos de exclusão social dos jovens (Instituto Cidadania, 2004). Ao mesmo tempo, a concepção de que estes são importantes atores na formulação dos programas e projetos que os envolvem e no processo de mobilização política do país passou a ganhar força (Boghossian $\&$ Minayo, 2009).

Desde então emergem e se dissipam discursos sobre protagonismo juvenil, empoderamento dos jovens, debates sobre o conceito de juventude, entre outros. O tema juventude se firma, em decorrência, como estratégia política nacional sendo criada, em 2006, a Política Nacional de Juventude e, em 2011, o Estatuto da Juventude. Boghossian e Minayo (2009), no artigo "Revisão sistemática sobre juventude e participação nos últimos dez anos", discutem as principais questões apontadas por pesquisadores de língua inglesa e portuguesa sobre o tema participação juvenil. Para tanto, analisaram livros, relatórios de pesquisa, artigos científicos e resumos de artigos, em língua inglesa e portuguesa, no período de 1997 a $2007^{1}$.

Dentre os estudos que investigam a produção científica sobre juventude e política encontra-se o capítulo 10 do segundo volume de "Estado da Arte sobre Juventude", de Sposito (2009), no qual são analisadas as pesquisas de pós-graduação brasileira sobre o tema entre os anos de 1999 e 2006 . A partir do levantamento de teses e dissertações no período, a autora introduz um conjunto de reflexões sobre as características da produção em pósgraduação sobre juventude e política nas áreas de Educação, Ciências Sociais (Sociologia, Ciências políticas e Antropologia) e Serviço Social. Afirma que as pesquisas analisadas apresentam uma concepção de política relacionada às disputas de poder, com maior produção voltada ao contexto escolar. Não ressalta o debate sobre o desaparecimento da juventude na cena política, como afirmava Abramo em 1997, mas conclui que novas formas de ativismo político e de práticas coletivas têm aglutinado os jovens e podem vir a se constituir objeto de estudo relevante neste campo temático.

De forma geral, estes estudos apresentam o que vem sendo produzido e discutido sobre jovens e política, como os movimentos estudantis, as questões relacionadas ao protagonismo juvenil, os valores e percepções com relação à participação dos jovens na política, as redefinições do conceito de jovens e juventude. Se por um lado esses estudos evidenciam que houve um avanço significativo no modo como se pensa a juventude a partir da década de 90 , por outro lado o modo como as políticas públicas voltadas aos jovens vem sendo problematizadas nas produções acadêmicas é questão importante a ser investigada, tendo em vista a necessária reflexão sobre as políticas e intervenções do Estado em relação a esse segmento da população.

Visando contribuir com o debate, este artigo apresenta e discute a produção acadêmica brasileira sobre juventude e políticas públicas divulgada em periódicos científicos brasileiros entre 2002 e 2011, tendo como fonte de buscas a base de dados SciELO (Scientific Electronic Library Online).

\section{Método}

Esta pesquisa, de caráter bibliográfico, se propõe a mapear e discutir a produção acadêmica sobre juventude e políticas públicas com o intuito de evidenciar os aspectos e dimensões que vêm sendo destacados e privilegiados pela comunidade acadêmica nos últimos dez anos. Por utilizar procedimentos de caráter inventariante e descritivo sobre o tema investigado, pode ser caracterizada como pesquisa do "estado do conhecimento" (Ferreira, 2002). Optamos como fonte de informações a Biblioteca Eletrônica do SciELO posto consistir em base de dados que concentra relevantes periódicos de diferentes áreas de conhecimento. Foi delimitado como período de investigação os últimos 10 anos (2002- 2011) posto a produção anterior ter sido foco das investigações referidas.

A pesquisa no SciELO foi realizada no mês de agosto de 2012 com os seguintes descritores: jovem e política; jovens e política; jovem e políticas; jovens e políticas; juventude e política; juventudes e política; juventude e políticas; juventudes e políticas. Encontramos 236 artigos, sendo que, entre esses, 63 estavam repetidos. Selecionamos, então, 173 artigos para serem analisados inicialmente por meio da leitura dos títulos, resumos e palavras-chave, visando identificar quais tinham as políticas públicas voltadas aos jovens como foco do discurso. Desse total, 58 artigos problematizam de alguma forma e com diferentes entonações, a questão das políticas públicas.

A leitura integral destes artigos foi realizada e foi possível verificar que, em relação ao tipo de produção, 28 dos 58 artigos analisados são pesquisas teóricas; 02 artigos consistem em relato de experiência e 28 são relatos de pesquisas empíricas. Os recursos metodológicos adotados nas pesquisas de campo relatadas foram: grupo focal, documentos, entrevistas, questionários, estudos de caso, pesquisas estatísticas, estudos exploratórios, estudo etnográfico. Não houve prevalência de um ou outro instrumento nas pesquisas relatadas e, em algumas delas, constatou-se a utilização de instrumentos variados.

Além dessas informações, as análises permitiram identificar a titulação e instituição dos autores; o ano de publicação e área de concentração dos periódicos; concepções de jovem, juventude e de políticas públicas. São essas informações e sua análise que apresentaremos como resultados, tendo em vista os objetivos e limites deste artigo.

\section{Resultados}

Entre 2002 e 2011 foram publicados 58 artigos em periódicos vinculados ao SciELO cujos focos foram as temáticas juventude e políticas públicas. Com relação à data de publicação destes trabalhos, apresenta-se a Figura 1, na qual podemos observar que o ano de 2008 concentra a maior parte dos artigos 
analisados, com 14 publicações, o que corresponde a $24 \%$ do total de artigos. Em 2006, 2009 e 2010, o número de trabalhos se reduz para metade, tendo sido encontrados sete artigos em cada ano (12\% do total analisado). O ano de 2007 também se destaca com nove trabalhos (16\%) e 2011 com oito (14\%). Em 2005 e 2004 foram identificados dois artigos em cada ano, em

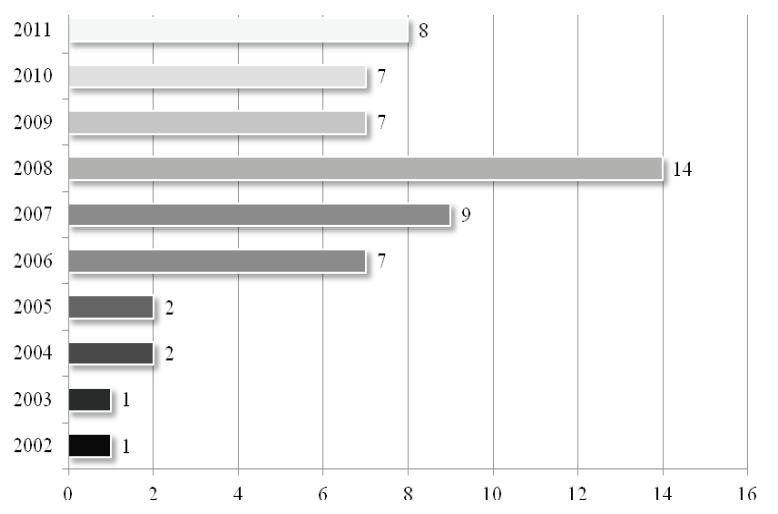

Figura 1

Ano de publicação dos artigos.

\section{3 e 2002 apenas um artigo.}

Em relação às áreas de concentração dos periódicos em que os artigos foram publicados, constata-se a prevalência de trabalhos na área da Educação, com 18 artigos no total (31\%). Em seguida destacam-se os periódicos relacionados à Psicologia, com 12 artigos (21\%) e às Ciências Sociais, com 11 trabalhos (19\%). Em evidência aparece também a área da Saúde, com 10 artigos (17\%). Completam o conjunto dos artigos analisados três em periódicos de esportes (3\%), dois de Serviço Social (3\%), um trabalho em periódico de Estudos de Gênero (2\%) e um (2\%) em periódico de Estudos Populacionais.

Os 57 artigos analisados foram escritos por 151 autores. Com relação à titulação, dentre eles há um predomínio de doutores (60\% do total), correspondendo a 88 autores. Além disso, 22 são mestres (15\%) e 14 são doutorandos (9\%). Observase ainda que cinco autores estão cursando o mestrado (3\%), 15 têm o ensino superior completo (10\%) e quatro estão cursando o ensino superior ( $3 \%)$. Constata-se também três autores cuja titulação não foi identificada.

Nos artigos analisados há um predomínio de autores (43, o que corresponde a $29 \%$ do total) da área da psicologia, seguidos por 35 autores (23\%) das ciências da saúde e 30 da educação (20\%). Encontrou-se também 20 trabalhos (13\%) de autores das ciências sociais e 20 de outras áreas como economia, administração e educação física, por exemplo. Foram também encontrados três autores cuja área de titulação não foi identificada.

Quanto à vinculação institucional dos autores analisados, as Universidades são as instituições que possuem maior número de pesquisadores. A Universidade de São Paulo se destaca com 22 autores dos artigos analisados (26\%), seguida pela Universidade Federal do Rio Grande do Sul e pela Universidade Federal Fluminense, com nove trabalhos cada (11\%). Destaca-se também a Universidade Federal de São Carlos com oito autores (10\%), a Pontifícia Universidade Católica do Rio Grande do Sul e a Universidade Federal do Rio de Janeiro com oito autores cada (8\%). Instituições com $6 \%$ ou menos compreendem 21 artigos analisados, tais como a Universidade Católica de Brasília (cinco autores), Secretarias Municipais (quatro autores) e, com três autores, a Universidade Estadual de Londrina, Universidade Católica de Pelotas e as Universidades Federais de Goiás e Brasília.

\section{Concepções de jovem e juventude}

A leitura e análise dos 58 artigos permitiu constatar que parte significativa dessa produção não apresenta uma concepção clara de juventude ou não a relaciona diretamente às temáticas política e políticas públicas, apesar dos descritores escolhidos para a busca perscrutarem essa relação.

Evidenciou-se também que alguns autores concebem a juventude dentro de uma faixa etária variada, outros trabalham com a noção de juventude como sinônimo de adolescência restringindo-se a demarcá-la como uma fase da vida. Vejamos de modo mais detalhado essas características encontradas.

Dentre os artigos que problematizam as concepções de jovem e juventude, Silva e Silva (2011) apresentam diferentes significados de juventude na sociedade contemporânea, a saber: juventude como fase de transição entre a adolescência e a vida adulta; juventude como uma categoria sociológica, relacionada à preparação para assumir o papel de adulto e compreendendo o período entre os 15 e 24 anos de idade, concepção essa adotada pela Organização Mundial da Saúde (OMS); e a concepção presente na Política Nacional de Juventude (PNJ) que considera jovem todo cidadão ou cidadã da faixa etária entre os 15 e os 29 anos. Após analisarem essas diferentes concepções as autoras consideram que "o uso da expressão "juventudes" representa o reconhecimento da necessidade de, ao se tratar de jovens, levar em conta que esse segmento constitui identidades e singularidades de acordo com a realidade de cada um" (Silva \& Silva, 2011, p. 664).

Já Frezza, Maraschin e Santos (2009), ao analisarem os discursos de dez agentes atuantes no Consórcio Social da Juventude (CSJ), apresentam as concepções de juventude presentes nesta política, categorizando-as em: juventude voluntária, juventude digitalizada, juventude trabalhadora e juventude vulnerabilizada.

Sposito e Corrochano (2005) não se propõem a definir o conceito de juventude, mas problematizam a categoria jovem ou juventude ao considerarem em nota que:

\footnotetext{
Trata-se não apenas de reiterar o caráter histórico e cultural da condição juvenil, mas de pressupor que os modelos simbólicos que tendem a compor uma imagem do que devem ser os jovens em uma determinada sociedade, além de normatizar sobre o trânsito para uma condição adulta considerada desejável, delimitam aquilo que pode ser reconhecido como o comportamento legítimo para o próprio momento do ciclo de vida. Apesar da diversidade de modelos, é possível considerar que algumas formas constituem dominância e passam a orientar a experiência concreta dos jovens, mas adaptadas às peculiaridades que decorrem de classe social, sexo, etnia, extração religiosa, condição
} 
de vida urbana ou rural. (2005, p.143)

Os outros estudos analisados não apresentam discussões sistemáticas sobre os conceitos de jovem e/ou juventude. De modo geral, apenas caracterizam o jovem ao descreverem os procedimentos para o recorte do público alvo investigado, identificando-o como faixa etária ou usuário de determinada política pública.

Do objetivo da pesquisa à conclusão, o jovem aparece nos trabalhos de Maggie (2006) e Silvério (2002) como alguém que vivencia o impacto das políticas públicas. Alguns estudos analisados reafirmaram a adolescência como período caracterizado por intensas mudanças emocionais (Cavalcante, Alves, \& Barroso, 2008; Souza et al., 2008), enquanto outros, com enfoque sociológico, identificam a juventude como fronteira etária que marca o momento em que o trabalho torna-se atividade principal (Rocha, 2008).

Embora marcos legais reconheçam o jovem como aquele com idade entre 15 e 29 anos, alguns estudos incluíram nesta categoria também aqueles com faixa etária menor ou maior que o definido por lei, considerando nestes casos aspectos sociais e os processos singulares de subjetivação.

Lima e Furtado (2008) caracterizam os jovens de baixa renda entre 15 e 18 anos como população de risco, vulneráveis ao recrutamento para o narcotráfico e mortes violentas e que, por isso, deveriam ser os beneficiários mais diretos de uma política de prevenção da violência na cidade. Frezza, Maraschin e Santos (2009), por sua vez, percebem tal foco e problematizam também a concepção de juventude vulnerabilizada que parece ser restrita aos jovens que são objeto das políticas públicas e, com isso, "o emblema de vulnerabilização conferido a esses jovens pode intensificar o processo de exclusão e, também, despotencializar o campo de ação dos mesmos" (p. 321)

Botelho, Silva, Kassab e Leite (2008) contextualizam o conceito de jovem histórico e culturalmente, tensionando as vertentes teóricas que apresentam o jovem que mora na rua ora como um inocente que é conduzido, ora como alguém perverso que age com violência deliberadamente. Os autores propõem considerar o ser jovem como o estado da adolescência, uma etapa da vida em que não se é criança, não se é adulto e que será vivenciada a partir do modo como o contexto cultural o significa. Ao longo do texto, por sua vez, menino de rua, adolescente e jovem aparecem na discussão como sinônimos para designar aquele que precisa de uma política pública específica no campo da saúde.

Essa equiparação conceitual foi percebida também no texto de Orlandi e Toneli (2008), que apresentam as expressões adolescente e juventude ora pareadas, ora em separado, ora como sinônimos. Consideram não existir um conceito universal, dada a participação histórico e cultural na significação dos mesmos, mas optam por definir adolescência a partir do conceito proposto pela Organização Mundial da Saúde.

A expressão jovem está pareada ao termo adulto, mas ambos sem definição em Rummert e Alves (2010). Juventude como "um período de preparação para o ingresso na vida adulta" é o conceito adotado por Bulgacov et al. (2011). Criança, jovem, moça e rapaz são termos abordados no estudo de Bellenzani,
Blessa e Paiva (2008) como sinônimos - sujeitos que estão, no dizer das autoras, "presos" e "marcados" por modelos, estereótipos e culturas sexuais.

Horta e Sena (2011) objetivaram, em seu estudo, verificar a concepção de juventude e adolescência que predominam nos documentos produzidos pelo Ministério da saúde de 1989 a 2008 e em artigos indexados na base SciELO e LILACS de 2004 a 2008. Os autores observam que a conceituação prevalente nos documentos oficiais do Ministério da Saúde é de adolescência marcada por uma delimitação etária de 10 a 19 anos e vinculada às transformações físicas, ao crescimento e desenvolvimento e à maturação sexual. Centram-se nos aspectos referentes aos riscos atribuídos aos adolescentes pela curiosidade e experimentação vivenciados nessa fase. Os autores apontam que os conceitos foram se modificando ao longo do tempo com a criação da Política Nacional de Juventude em 2003.

Tomadas como sinônimos na área da saúde, principalmente nos campos da psicologia, enfermagem e medicina, e como categoria supostamente homogênea pelas políticas públicas, essa imprecisão conceitual acaba por obscurecer as práticas sócio-políticas para esse grupo do que esclarecê-las. Até mesmo nas bases científicas da saúde, os conceitos de adolescência e juventude aparecem como sinônimos (Horta \& Sena, 2011).

Nessa direção, a análise da concepção de juventude nos textos que tratam sobre políticas públicas evidenciam, tal como Andrade e Bórgus (2010), o desafio constante de desconstrução de aspectos dos jovens dados como homogêneos e independentes do contexto em que estejam imersos.

\section{Concepção de políticas públicas}

Dentre o conjunto de artigos selecionados a partir dos descritores anteriormente referidos, 12 se referem a políticas de educação, como educação profissional, educação de jovens e adultos, educação no campo; outros 14 artigos tem relação com políticas de saúde e tematizam os jovens em situações de risco, com foco no uso de drogas, gravidez precoce e concepções de juventude nos programas de saúde; 11 artigos tratam de políticas de assistência social voltadas para jovens: jovens em situação de medida de internação, em situação de abrigamento, em situação de rua; seis artigos focam políticas de trabalho. Encontramos, ainda, três artigos que discutem as políticas públicas para juventude de modo abrangente. E, por fim, três artigos que discutem políticas de esporte e lazer; três de políticas de gênero e outros três de políticas públicas direcionadas às questões de raça e etnia. Sobre questões contemporâneas como violência urbana e inclusão digital, encontramos apenas um artigo relacionado a cada um destes temas.

Quanto às concepções de políticas públicas nos textos analisados, identificamos que a maioria não apresenta uma concepção clara, tampouco um posicionamento frente aos termos. Muitos se limitam a apontar a necessidade de políticas públicas eficazes destinadas à juventude em diferentes áreas temáticas. Em virtude do foco deste artigo, destacaremos os artigos que problematizam tal relação.

Frezza, Maraschin e Santos (2009) afirmam que "as ações de políticas públicas de juventude podem tanto contribuir para criar novos sentidos e práticas para e pelos jovens como 
podem, simplesmente, reforçar as concepções e modos de viver dominantes reservados à juventude dita em maior vulnerabilidade social" (p.316). O artigo de Silva e Silva (2011), por sua vez, aponta que:

Um dos principais desafios para a implementação de uma política pública asseguradora de direitos sociais para a juventude é obter a mobilização permanente da sociedade civil, conjugada à vontade e à decisão política para ampliar, aperfeiçoar, avaliar e monitorar, além de realizar o controle social democrático das atuais iniciativas.” (p.670)

O posicionamento de Silva e Silva (2011) é de que as políticas públicas para juventude precisam se efetivar como emancipatórias e adequadas às necessidades específicas das diferentes juventudes.

Sposito e Carrano (2003) se propõem a analisar as políticas públicas com foco na juventude e conceituam política pública da seguinte forma:

Em sua acepção mais genérica, a idéia de políticas públicas está associada a um conjunto de ações articuladas com recursos próprios (financeiros e humanos), envolve uma dimensão temporal (duração) e alguma capacidade de impacto. Ela não se reduz à implantação de serviços, pois engloba projetos de natureza ético-política e compreende níveis diversos de relações entre o Estado e a sociedade civil na sua constituição. Situase também no campo de conflitos entre atores que disputam orientações na esfera pública e os recursos destinados à sua implantação. É preciso não confundir políticas públicas com políticas governamentais. (p. 17)

$\mathrm{Na}$ concepção das autoras, evidencia-se a relação entre política pública e disputas sociais. Em outro texto, Spósito e Corrochano (2005) analisam que as políticas destinadas a jovens pobres, com base na transferência de renda, "são normativas: prescrevem ou enfatizam normas, significados ou conteúdos simbólicos que incidem sobre expectativas de disseminação de condutas juvenis consideradas adequadas para um determinado tempo e espaço." (p. 146)

Nogueira (2011) acresce ao destacar que a cultura se tornou ferramenta para fomentar formas de participação política e social. Exemplifica com as práticas de hip hop, rap, funk e com produções que não só retratam a realidade, mas que também, de alguma forma, exprimem uma reivindicação social. Posteriormente, traz a prática esportiva como um vetor político e cultural de experiências positivas focadas na participação, no reconhecimento de potencialidades, no desenvolvimento de capacidades, na afirmação das diferenças e no fortalecimento de identidades. Rodríguez (2009) também valoriza a política pública como modo de "potencializar a formação de sujeitos em uma práxis transformadora” (p.327).

Identificamos, portanto, que política e políticas públicas são tratadas nos textos a partir de diversos objetivos, possibilidades e meios. Apontam necessidades, contribuem com a construção de sentidos e práticas, mobilizam a sociedade, controlam pessoas, emancipam contextos, são normativas e movimentam a cultura. De modo geram, prevalece nos estudos analisados uma concepção idealista de políticas públicas.
Há em contrapartida textos em que a reflexão vai em direção à política e políticas públicas como um campo ideológico institucionalizado, que cerceia ou concede oportunidades (Botelho et al., 2008; Carvalho, 2004; Rummert \& Alves, 2010). Outros não discutem o que entendem por política pública e apenas a colocam como alvo de suas reflexões sem, entretanto, explicitar realmente de que maneira suas contribuições podem vir a ser incorporadas. Em poucos textos a questão política é tratada como um campo de lutas e conquistas marcado por tensões (Garcia, 2010; Ribeiro, 2006; Sposito \& Carrano, 2003). Maggie (2006) e Silvério (2002) identificam a concepção de políticas públicas como o exercício de poder, mas enfatizam que as mesmas possuem claras demarcações sociais.

\section{Discussão}

O estudo que teve por objetivo discutir a produção acadêmica sobre jovem, juventude e políticas públicas divulgada em periódicos científicos brasileiros entre 2002 e 2011 evidenciou a concentração de estudos sobre políticas públicas de educação, saúde e assistência social. Tal fato pode ser compreendido ao considerarmos que estas três políticas concentram grande parte dos serviços e programas de atendimento à infância e juventude, conforme estabelece o Estatuto da Criança e do Adolescente (ECA). Observou-se ainda que poucos estudos sobre políticas públicas e juventude debatem questões contemporâneas como gênero, homofobia, inclusão digital e violência urbana, e inexistem na base de dados investigada produções abordando jovens rurais e indígenas. Esse aspecto foi também identificado por Sposito (2009) em seu estudo.

Em relação ao modo como as concepções de jovem e juventude são assumidas nos diversos estudos e se desdobram ou aparecem nas possibilidades ofertadas a eles nas diversas políticas públicas, observamos que os estudos analisados dão ênfase às políticas públicas voltadas ao jovem em situações entendidas como de risco, ratificando a construção social que relaciona juventude e situações de risco. A visibilidade dada à juventude brasileira, nos textos analisados, exprime o que alguns estudos vêm questionando sobre o modo como é concebida: alvo de preocupações, vítima de problemas e foco de políticas públicas repressivas e preventivas (Abramo, 1997; Bocco, 2009).

Nos estudos investigados prevalece o uso de expressões como fase da vida, fase de transição, estágio, preparação para a vida adulta, como se o ser jovem fosse um vácuo existencial desprovido de direitos, deveres, limites e também possibilidades de existência. Ao adotarem a perspectiva de construção do sujeito em fases ou estágios, a ênfase na faixa etária segue dominante.

Contrapondo-se a essa perspectiva, alguns estudos não incluídos no conjunto de artigos analisados posto não constarem no SciELO consideram que jovem e juventude são condições marcadas por contextos culturais. Machado (2011), por exemplo, analisa que na década de 70 o ser jovem foi definido pelas práticas de transição à inserção na sociedade através do trabalho e da escola; a década de 80 significou a juventude como uma parte da população politicamente apática; a década de 90 , por sua vez, redefine o ser jovem a partir de práticas culturais de massa que estão devotadas ao consumo e à construção de uma 
“cultura juvenil” (p. 70). Além disso, Machado (2011) destaca a antecipação etária do jovem na dinâmica laboral, principalmente o que vive no ambiente rural.

Groppo (2011), por sua vez, considera a juventude a partir de uma perspectiva crítica, o que permite compreender "as continuidades e descontinuidades" da condição juvenil nesse início de século XXI, marcado por práticas de participação e passividade, rebeldia e aceitação, radicalismo e delinquência. Com esse enfoque, não é possível homogeneizar a noção de juventude e enquadrá-la por uma faixa etária ou defini-la apenas por condições culturais. Embora a ONU a defina como a faixa etária entre os 15 e os 24 anos e mesmo existindo características biológicas e subjetivas semelhantes entre os sujeitos, a homogeneização contrapõe-se à possibilidade de compreensão da multiplicidade de experiências dos jovens e das singularidades que os conotam.

Essa perspectiva crítica, no entanto, não se apresenta para a maioria dos artigos analisados. Estes delegam ao ser jovem o lugar social de passividade diante dos serviços ofertados pelas políticas públicas a eles direcionadas. Em menos de $10 \%$ dos artigos analisados é reservado ao jovem o lugar de coautor, partícipe do planejamento, organização e execução das políticas públicas. Tal indicador é preocupante, a nosso ver, pois é importante que as políticas públicas direcionadas aos jovens estejam apoiadas em suas demandas e interesses, que considerem suas particularidades, potencialidades e valorizem suas experiências e possibilidades de vir a ser.

\section{Considerações finais}

A pesquisa realizada permitiu constatar que, ao se referirem aos jovens, predominam nos artigos analisados resquícios da concepção de uma vida vivida em fases, com estágios claramente marcados pela entrada e saída do trabalho. São trabalhos em que se evidencia a lógica da tutela (Birman, 2009), seja da família, do Estado e de outras Instituições, inclusive a academia. No entanto, é possível observar que as análises empreendidas nesses estudos, de um modo geral, constituem um movimento de retomada e avanço do que foi conquistado e do que é preciso, ainda, ser garantido à população juvenil. Se alguns textos engessam a concepção de juventude atrelada ao risco, especialmente nas áreas da saúde e assistência social, outros flexibilizam esta relação a partir do debate sobre os avanços necessários nas políticas em diferentes setores sociais.

Embora uma parte dos artigos não se detenha sobre a concepção de juventude, encontra-se, ainda, na diversidade de maneiras de conceituar ou mesmo determinar o que seja juventude, ponto crucial de expressão das atuais contradições sociais relacionadas a esse debate. Vale destacar, também, o lugar em que a produção acadêmica se coloca. Compreendida como rede de relações que tecem a práxis do conhecimento, esta pouco questiona as condições que fazem do jovem esse sujeito descrito nos artigos como marcado por características de um estágio da vida, susceptível a riscos e carente de intervenções institucionais. Os artigos aqui em estudo não se apresentam, em sua maioria, como agentes co-partícipes da denúncia, mobilização e construção de uma sociedade de direitos mais acessíveis a todos.

As políticas públicas vistas como ações advindas de outras instâncias, por sua vez, são lançadas conclusivamente como solução para os casos apresentados, mas sem um posicionamento crítico que questione a crença de que juventude brasileira, nessa primeira década do século XXI, esteja apática aos movimentos coletivos e se mostre dependente dos representantes de outras "fases" da vida. A maioria dos artigos parece perpetuar a lógica individualista do quebra-cabeça capitalista, "em que cada um faz a sua parte" (Resende, 2012). A produção acadêmica descreve, o Estado determina políticas públicas, e o jovem? Esse, para os trabalhos em foco, está em trânsito pela vida aguardando o amadurecimento, supostamente expropriado das possibilidades de contrariar, denunciar e participar das decisões acerca dos direitos da coletividade em que está inserido. Porém, as diversas manifestações de jovens em variados campos e condições, nas vias das cidades, nos muros e paredes plácidos violentados com seus traços e formas, em resistências diversas, algumas pouco compreensíveis em sua dimensão opositiva, anunciam, ao que parece, o seu contrário. Desafio se faz escutar o que é dito por essas vias outras, supostamente desconhecidas e não raro invisibilisadas.

\section{Referências}

Abramo, H. W. (1997). Considerações sobre a tematização social da juventude no Brasil. Revista Brasileira de Educação. (Número especial - Juventude e contemporaneidade), 5(6), 73-90.

Andrade, E. A., \& Bógus, C. M. (2010). Políticas públicas dirigidas à juventude e promoção da saúde: Como a proposta de auxiliares da juventude foi traduzida em prática. Interface (Botucatu), 14(35), 853-866.

Bellenzani, R., Blessa, C., \& Paiva, V. (2008). Scripts em cena: HIV e mercado sexual no contexto turístico. Psicologia em Estudo, 13(4), 653-662.

Birman, J. (2009). Juventude e condição adolescente na contemporaneidade: Uma leitura da sociedade brasileira de hoje. In Bocayuva, H. \& Nunes, S. A. (Orgs.), Juventude, subjetivações e violências. Rio de Janeiro: Contra Capa. Bocco, F. (2009). Cartografias da Infração Juvenil. Porto Alegre: Abrapso Sul. Boghossian, C. O, \& Minayo, M. C. S. (2009). Revisão sistemática sobre juventude e participação nos últimos 10 anos. Saúde e Sociedade. (São Paulo), 18(3), 411-423.

Botelho, A. P., Silva, S. L. F., Kassab, M. J., \& Leite, L.C. (2008). Meninos de rua: Desafiliados em busca de saúde mental. Psicologia em Estudo, 13(2), 361-370.

Bulgacov, Y. L. M., Cunha, S. K., Camargo, D., Meza, M. L., \& Bulgacov, S. (2011). Jovem empreendedor no Brasil: A busca do espaço da realização ou a fuga da exclusão? Revista de Administração Pública, 45(3), 695-720.

Carvalho, M. E. P. (2004). Modos de educação, gênero e relações escola-família. Cad. Pesqui, 34(121), 41-58.

Cavalcante, M. B. P. T., Alves, M. D. S., \& Barroso, M. G. T. (2008). Adolescência, álcool e drogas: Uma revisão na perspectiva da promoção da saúde. Escola Anna Nery Revista de Enfermagem, 12(3), 555-559.

Ferreira, N. S. A.(2002). As pesquisas denominadas "estado da arte". Educação \& Sociedade, 23(79), 257-272.

Frezza, M., Maraschin, C., \& Santos, N. S. (2009). Juventude como problema de políticas públicas. Psicolologia e Sociedade, 21(3), 313-323.

Garcia, M. M. A. (2010). Políticas educacionais contemporâneas: Tecnologias, imaginários e regimes éticos. Revista Brasileira de Educação, 15(45), 445-455.

Groppo, L. A. (2011). Condição juvenil e modelos contemporâneos de análise sociológica das juventudes. In J. T. P. Sousa \& L.A. Groppo (Orgs.), 
Dilemas e contestações das juventudes: No Brasil e no mundo (pp. 11-29). Florianópolis: UFSC.

Horta, N. C., \& Sena, R. R. (2010). Abordagem ao adolescente e ao jovem nas políticas públicas de saúde no Brasil: Um estudo de revisão. Physis, 20(2), 475-495.

Instituto Cidadania. (2004) Projeto Juventude. Documento Final. São Paulo.

Lima, G., \& Furtado, V. (2008). Política pública dos telecentros e prevenção da violência. Sociologias, 20, 192-223.

Machado, V. (2011). O conceito de juventude: Uma abordagem cultural dessa fase da vida. In J. T. P. Sousa \& L. A. Groppo (Orgs.), Dilemas e contestações das juventudes: No Brasil e no mundo (pp. 31-74). Florianópolis: UFSC.

Maggie, Y. (2006). Racismo e anti-racismo: Preconceito, discriminação e os jovens estudantes nas escolas cariocas. Educação \& Sociedade, 27(96), 739-751.

Nogueira, Q.W.C. (2011). Esporte, desigualdade, juventude e participação. Revista Brasileiras de Ciências e Esporte, 33(1), 103-117.

Orlandi, R., \& Toneli, M. J. F. (2008). Adolescência e paternidade: Sobre os direitos de criar projetos e procriar. Psicologia em Estudo, 13(2), 317-326.

Resende, A. C. A. (2012). Psicologia social e políticas públicas: A que será que se destinam? In J. C. Chaves (Org.), Psicologia social e politicas públicas: contribuições e controvérsias (pp. 19-33).Goiânia: PUC Goiás.

Ribeiro, M. (2006). Exclusão e educação social: Conceitos em superfície e fundo. Educação \& Sociedade, 27(94), 155-178.

Rocha, S. (2008). A inserção dos jovens no mercado de trabalho. Caderno CRH,
21(54), 533-550.

Rodríguez, L. M. (2009). Educação de jovens e adultos na América Latina: políticas de melhoria ou de transformação: Reflexões com vistas à VI CONFINTEA. Revista Brasileira de Educação, 14(41), 326-334.

Rummert, S. M., \& Alves, N. (2010). Jovens e adultos trabalhadores pouco escolarizados no Brasil e em Portugal: alvos da mesma lógica de conformidade. Revista Brasileira de Educação, 15(45), 511-528.

Silva, R. S., \& Silva, V.R. (2011). Política Nacional de Juventude: Trajetória e desafios. Caderno CRH, 24(63), 663-678.

Silvério, V. R. (2002). Ação afirmativa e o combate ao racismo institucional no Brasil. Caderno de Pesquisa, 117, 219-246.

Souza, L. D. M., Silva, R. S., Godoy, R. V., Cruzeiro, A. L .S., Faria, A. D. Pinheiro, R. T., ... Silva, R. A. (2008). Sintomatologia depressiva em adolescentes iniciais: Estudo de base populacional. Jornal Brasileiro de Psiquiatria, 57(4), 261-266. doi: 10.1590/S0047-20852008000400006

Sposito, M. P. (2009). Estado da arte sobre juventude na pós-graduação brasileira: Educação, ciências sociais e serviço social (1999- 2006). Belo Horizonte: Argvmentvm.

Sposito, M. P., \& Carrano, P. C. R. (2003). Juventude e políticas públicas no Brasil. Revista Brasileira de Educação, 24, 16-39.

Sposito, M. P., \& Corrochano, M. C. (2005). A face oculta da transferência de renda para jovens no Brasil. Tempo Social: Revista de Sociologia da USP, 17(2), 141-172.

1. Outros importantes documentos que apresentam dados sobre a relação entre jovens e política no Brasil, mas não consistem análises sistemáticas de produção científica, são: o documento final do Projeto Juventude, realizado pelo Instituto Cidadania em 2004; e o relatório da pesquisa "Diálogo nacional para uma política pública de juventude!" (2008), realizada pelo Instituto Polis e pelo Instituto Brasileiro de Análises Sociais e Econômicas com oito mil jovens de todo o país.

Andréa Vieira Zanella, Doutora em Psicologia da Educação pela Pontifícia Universidade Católica de São Paulo, pós-doutorado na Universidade La Sapienza, de Roma e Universidade Federal do Rio Grande do Sul, é professora associada do departamento e programa de pós-graduação em Psicologia da Universidade Federal de Santa Catarina e Bolsista Produtividade do CNPq. Endereço para correspondência: Universidade Federal de Santa Catarina, Centro de Filosofia e Ciências Humanas, Departamento de Psicologia - Campus Universitário- Trindade CEP 88040-900 - Florianópolis, SC - Brasil. Telefone: (48) 37219984. Email: avzanella@gmail.com

Apoliana Regina Groff, Mestre em Psicologia pela Universidade Federal de Santa Catarina, é

Doutoranda em Psicologia pelo Programa de Pós-Graduação em Psicologia da Universidade Federal de Santa Catarina. Email: poligroff@gmail.com

Dâmaris Oliveira Batista da Silva, Mestre em Psicologia pela Universidade Federal de Santa Catarina, é professora da graduação em Administração e Relações Internacionais da Universidade do Sul de Santa Catarina.Email: damarisobs@gmail.com

Laura Kemp de Mattos, Mestre em Psicologia pela Universidade Federal de Santa Catarina, é

Doutoranda em Psicologia pelo Programa de Pós-Graduação em Psicologia da Universidade Federal de Santa Catarina. Email: kemp.laura@gmail.com

Janaina Rocha Furtado, Mestre em Psicologia pela Universidade Federal de Santa Catarina, é Pesquisadora do Centro Universitário de Estudos e Pesquisas sobre Desastres da Universidade Federal de Santa Catarina. Email: janaina.ufsc@gmail.com

Neiva de Assis, Mestre em Psicologia pela Universidade Federal de Santa Catarina, é professora e psicóloga do Instituto Federal de Santa Catarina. Email: neivapsi@hotmail.com 